\title{
A BPA survey of recently appointed consultants
}

\author{
S W Lenton, P J Dison, L C Haines
}

This is the first article in a series on medical education.

\begin{abstract}
A postal survey of recently appointed consultant paediatricians was undertaken to determine whether they perceived their training had adequately equipped them for their current job. The response rate was 69\% (207/299). After excluding replies from consultants trained outside the UK the analysis was carried out on 167 replies.

Trainees held a mean $5 \cdot 2$ posts during general and higher professional training, necessitating a mean 1.8 house moves. Altogether $82 \%$ felt moves were beneficial to training but $46 \%$ found moves 'very disruptive' to family life. Only $12 \%$ of district general hospital and $22 \%$ of teaching hospital senior registrars took two research sessions a week. Supervision and training in research was absent or poor for more than $60 \% ; 24 \%$ felt major changes and $55 \%$ moderate changes were needed to current training. Training in non-clinical skills was particularly in demand and a curriculum for both trainers and trainees with regular appraisals is required. Research at senior registrar level needs review and educational methods improved to achieve better training in a shorter period.

(Arch Dis Child 1994; 71: 381-385)
\end{abstract}

Recent papers from outside the UK suggest that paediatricians are seeing less organic disease and more problems described as 'new morbidity'. 12 This new morbidity includes learning and school problems, behaviour/ hyperactivity problems, enuresis and encopresis, headache and abdominal pain, adolescent problems, developmental disorders, child at risk/abuse, and parent/family counselling. A follow on paper ${ }^{3}$ proposes a mismatch between training and consultant practice in Australia - a situation that might be true in the UK for both general paediatric practice and the demands for specialty practice, which has developed significantly in the last decade.

Within the UK, changing patterns of childhood morbidity have been accompanied by other changes affecting the paediatric consultant. The reforms in NHS management, shorter junior doctors hours, the development of educational contracts, senior house officer appraisals, and an increased expectation for more formal training all add to consultant responsibilities and demand a wider range of skills from newly appointed consultants than colleagues appointed a decade ago.

There is little information about whether paediatric training in the UK equips today's consultants for the demands placed upon them. The British Paediatric Association (BPA) Academic Board therefore undertook a postal survey to assess the current situation.

\section{Method}

A semistructured questionnaire relating to consultants' general and higher professional training was devised by two members of the BPA Academic Board (SWL, PJD) and presented to and modified by the academic board on two occasions. The questionnaire was then piloted on four consultant paediatricians to assess 'ease of use'.

The questionnaire was sent in July 1993 to all consultants known to have been appointed within four years of the September 1992 BPA manpower census and a follow up letter sent in August 1993.

The questionnaire sought information about their actual experience in general and higher professional training grades in the UK and their opinions about the appropriateness of the training in relation to their current job. Consultants who received most of their training outside the UK were asked to return the questionnaires uncompleted. Comments were also invited on all issues and all responses were read by two board members (SWL, PJD).

The results were analysed using Smart computer software by a member of the BPA secretariat $(\mathrm{LCH})$ and are summarised below.

\section{Response}

After the initial circulation of the questionnaires, all consultants were sent a reminder letter. A total of 207/299 questionnaires were returned giving a response rate of $69 \%$. Of these 35 were returned uncompleted because consultants had spent a significant time abroad while training, and five arrived too late to be analysed. The analysis was therefore carried out on a total of 167 questionnaires. The majority of consultants participating in the survey $(90 \%)$ had been in post for four or less than four years and received all their training in the UK. The remaining $10 \%$ of consultants, although spending some time abroad, had
Correspondence to: Dr S W Lenton, Community Child Health Department, BA1 3QE 
undergone training in the UK of sufficient length to be able to contribute to the survey.

\section{Results}

POST TYPE

Table 1 provides a breakdown of the posts held by consultants participating in the survey.

Table 1 Posts held by consultants in the survey $(n=167)$

\begin{tabular}{lr}
\hline Post type & No \\
\hline Mainly general paediatrics in a DGH & 64 \\
Specialty paediatrics in a DGH & 6 \\
Mainly general paediatrics in a teaching hospital & 8 \\
Specialty paediatrics in a teaching hospital & 25 \\
Academic (either university or A+B posts) & 16 \\
Community paediatrics in child development centre & 17 \\
Community paediatrics - community based & 31
\end{tabular}

$\mathrm{DGH}=$ district general hospital.

Table 2 Time spent in training grades

\begin{tabular}{lll}
\hline Training grade & $\begin{array}{l}\text { Mean time } \\
\text { in post } \\
\text { (years) }\end{array}$ & $\begin{array}{l}\text { Mean time for } \\
\text { those in grade } \\
\text { (years) }\end{array}$ \\
\hline NHS senior house officer & 2.4 & $2 \cdot 5(\mathrm{n}=159)$ \\
NHS registrar & 2.5 & $2 \cdot 6(\mathrm{n}=160)$ \\
NHS senior registrar & 1.9 & $2 \cdot 9(\mathrm{n}=109)$ \\
$\begin{array}{l}\text { Research post at registrar level } \\
\text { or equivalent }\end{array}$ & 1.2 & $2 \cdot 1(\mathrm{n}=96)$ \\
$\begin{array}{l}\text { Research post at senior registrar } \\
\text { level or equivalent }\end{array}$ & 0.5 & $2 \cdot 4(\mathrm{n}=34)$ \\
SCMO & 0.8 & $4 \cdot 0(\mathrm{n}=33)$ \\
Lecturert & 0.9 & $3.1(\mathrm{n}=50)$
\end{tabular}

^Mean of all 167 consultants

tHonorary NHS registrars or senior registrars.

TIME SPENT IN TRAINING GRADES

Consultants were asked about the length of time spent in training grades. The mean length of time spent in the various posts for consultants is shown in table 2 .

The median length of time in general and higher professional training before consultant appointment was 10.5 years (range 5-28 years, mean 10.75 ). The time spent in training grades was also analysed in relation to the current post held. Table 3 illustrates the mean time in the various grades for all paediatricians in district general hospitals and teaching hospitals, those in academic posts, and community paediatricians.

There was no significant difference in the length of training for these groups of consultants. However, if senior community medical officer (SCMO) posts, which are not recognised training grades, are excluded from the analysis then the duration of training for 'community' posts in training grades is $2 \cdot 4$ years shorter than their 'hospital' colleagues.

Table 3 Time in training grade posts ${ }^{\star}$ (years) in relation to current job

\begin{tabular}{lcccc}
\hline Training grade & $\begin{array}{l}D G H \\
(n=70)\end{array}$ & $\begin{array}{l}\text { Teaching hospital } \\
(n=33)\end{array}$ & $\begin{array}{l}\text { Community } \\
(n=49)\end{array}$ & $\begin{array}{l}\text { Academic } \\
(n=16)\end{array}$ \\
\hline Senior house officer & $2 \cdot 5$ & $2 \cdot 4$ & $2 \cdot 3$ & $2 \cdot 7$ \\
Registrar & $2 \cdot 6$ & $2 \cdot 3$ & $2 \cdot 5$ & $1 \cdot 9$ \\
NHS senior registrar & $2 \cdot 4$ & $2 \cdot 1$ & $1 \cdot 2$ & $0 \cdot 1$ \\
Research registrar & $1 \cdot 2$ & $1 \cdot 4$ & 0.9 & $1 \cdot 7$ \\
Research senior registrar & $0 \cdot 3$ & $0 \cdot 6$ & 0.7 & 0.7 \\
SCMO & $0 \cdot 2$ & $0 \cdot 2$ & $2 \cdot 4$ & 0 \\
Lecturer & $0 \cdot 8$ & $1 \cdot 2$ & 0.6 & $2 \cdot 2$ \\
Total & 10.0 & $10 \cdot 2$ & 10.6 & $9 \cdot 3$ \\
\hline
\end{tabular}

$\mathrm{DGH}=$ district general hospital

^Not all consultants held all posts during their training.
The mean time in a SCMO post was four years reflecting personal accreditations.

POSTS HELD

The mean number of posts held during general and higher professional training was $5 \cdot 2$ (range $1-15$ ) in a mean of 3.6 district health authorities necessitating a house move on average 1.8 times during registrar/senior registrar training.

Eighty two per cent of consultants felt that the moves between jobs were beneficial to their training and only $4 \%$ felt that these moves had a negative effect. A few felt that with better organisation fewer moves would have been needed.

Frequent moves did have a negative effect on family and social life: $46 \%$ of consultants reported that these moves were 'very disruptive' and only $16 \%$ reported positive effects for their families.

\section{TRAINING EXPERIENCE IN RELATION TO} CURRENT JOB

Consultants were asked to assess the value of their experience in district general hospitals and teaching hospitals in relation to their current job. The results are shown in table 4 .

Analysis of the results showed that district general hospital and teaching hospital experience was judged to be equally useful by newly appointed consultants. Overall $18 \%$ of consultants did not have any training experience in a district general hospital whereas only $4 \%$ had no experience in a teaching hospital.

Table 4 Value of hospital experience; figures are number (\%)

\begin{tabular}{lll}
\hline Score & $D G H(n=128)$ & Teaching hospital $(n=153)$ \\
\hline Very useful & $94(73)$ & $111(73)$ \\
Useful & $30(23)$ & $38(25)$ \\
Not useful & $4(3)$ & $4(3)$
\end{tabular}

$\mathrm{DGH}=$ district general hospital .

RESEARCH IN NHS SENIOR REGISTRAR POSTS

Consultants were asked about the number of research sessions they were able to take and also to rate their research training and supervision of the research (table 5). Only $12 \%$ of trainees in district general hospitals and $22 \%$ in teaching hospitals were able to take two or more sessions and $55 \%$ and $43 \%$ respectively took no research sessions.

\section{RESEARCH POSTS}

The consultants who had held a research post during their paediatric training were asked for their views on research experience in these posts. A total of $65 \%$ of consultants had held such posts. Of these $55 \%$ had had full time research contracts with 10 or 11 sessions allocated for research. Overall $83 \%$ felt that the time allowed for research was adequate. The quality of both training and supervision was 
Table 5 Research sessions available for senior registrars; figures are number (\%)

\begin{tabular}{lllll}
\hline Senior registrar post & 0 & 1 & 2 & $>2$ \\
\hline DGH (n=91) & $50(55)$ & $30(33)$ & $11(12)$ & 0 \\
Teaching hospital $(\mathrm{n}=136)$ & $59(43)$ & $47(35)$ & $24(18)$ & $6(4)$ \\
\hline
\end{tabular}

$\mathrm{DGH}=$ district general hospital.

significantly better in clinical fellowships than in senior registrar jobs (table 6).

VIEWS ON THE CONTENT OF TRAINING

Consultants were asked if changes are required in paediatric training to adequately equip trainees to perform at consultant level. Fifty five per cent of paediatricians felt that moderate changes were needed and $24 \%$ felt major changes were appropriate. Only $6 \%$ thought no changes were necessary, the rest wanted minor reforms.

\section{STATEMENTS ABOUT PAEDIATRIC TRAINING}

Consultants were asked if they agreed or disagreed with 10 statements about paediatric training. The results are shown in table 7 . The analysis shows that fewer than half of the consultants in the survey felt that their training had equipped them well to manage a paediatric team, with two thirds agreeing that training needs are currently taking second place to service commitments.

\section{TRAINING EXPERIENCE IN PAEDIATRIC}

SPECIALTIES

Consultants were asked to assess their training in 22 specialist areas of paediatrics and in relation to their current working practice. The areas were: general paediatrics; metabolism; neonatology; intensive care; gastroenterology; respiratory; nephrology; endocrinology; immunology/infectious disease; neurology; haematology/oncology; child protection; public health medicine; adoption and fostering; genetics/genetic counselling; psychiatry; NHS management/committee work; teaching; accident and emergency; cardiology; dermatology; and rheumatology.

The overall analysis identified training in NHS management/committee work, public health medicine, psychiatry, genetics, and dermatology to be the weakest areas. The best training experiences were in general paediatrics, neonatology, intensive care, neurology, and respiratory paediatrics.

The results were analysed in more detail by comparing the answers of consultants working in district general hospitals, teaching hospitals, and the community. The results are shown in table 8 .
The results show that paediatricians regardless of where they currently work identified similar strengths and weaknesses in current training programmes. Training in NHS management/committee work was inadequate and other areas of weakness were public health medicine, psychiatry, dermatology, neurology, genetics and genetic counselling, rheumatology, and adoption and fostering.

Clinical specialty areas where training was good are shown in table 9.

There were very few clinical specialties that were over-represented in consultants' training experience. The one exception was the $25 \%$ of community consultants who felt there had been too much neonatology in their training.

An assessment of how consultants in their present working environments rated their training can be obtained by a comparison of the number of areas scored as providing good training. Consultants working in academic posts scored the highest with an overall score of 6.6 areas per consultant rated as good. For paediatricians in teaching hospitals and district general hospitals the scores were 6.01/ consultant and 5.3/consultant respectively. Community paediatricians scored only $4 \cdot 3$ areas/consultant as providing good training.

\section{Discussion}

The balance between service commitment and training is a delicate one and the large number of comments received reflects the strength of feeling of many paediatricians on this issue. Seventy nine per cent of respondents felt that significant changes were necessary and more than $50 \%$ added comments.

One dominant theme related to the number of moves required during general and higher professional training and the strain this imposed on personal relationships and marriage. At least three people cited this as a cause for divorce. The mean number of moves during higher professional training was only 1.8 but comments indicated that moving was often avoided either by choosing to live in a large city which offered a variety of hospital experience or by trainees commuting long distances to avoid disrupting the family. The latter was not without personal cost and demoralisation. Many others felt that the most unstable period was during general profession training. Those married to other doctors found life particularly difficult and in many instances their spouse's (or their own) career suffered. Others delayed marriage/children 'till the worst was over' but single people also found the insecurity and loss of support networks associated with moving difficult to cope with and this resulted in clinical depression in at

Table 6 Quality of training and supervision of research; figures are number (\%)

\begin{tabular}{|c|c|c|c|c|c|c|c|c|}
\hline & \multicolumn{4}{|l|}{ Training } & \multicolumn{4}{|c|}{ Supervision } \\
\hline & None & Poor & Adequate & Good & None & Poor & Adequate & Good \\
\hline $\begin{array}{l}\text { Senior registrar in DGH } \\
\text { Senior registrar in teaching hospital } \\
\text { Research fellow }\end{array}$ & $\begin{array}{l}24(26) \\
35(26) \\
4(4)\end{array}$ & $\begin{array}{l}48(53) \\
74(56) \\
38(36)\end{array}$ & $\begin{array}{l}13(14) \\
16(12) \\
28(26)\end{array}$ & $\begin{array}{l}6(7) \\
8(6) \\
37(35)\end{array}$ & $\begin{array}{l}13(14) \\
13(10) \\
0\end{array}$ & $\begin{array}{l}42(47) \\
63(49) \\
30(28)\end{array}$ & $\begin{array}{l}20(22) \\
30(23) \\
35(33)\end{array}$ & $\begin{array}{l}15(17) \\
22(17) \\
41(39)\end{array}$ \\
\hline
\end{tabular}

DGH=district general hospital. 
Table 7 Response to statements (\%)

\begin{tabular}{lrr}
\hline Statement & $Y e s$ & $N o$ \\
\hline Formal performance appraisal should be held during and on completion of each & & \\
grade & 83 & 4 \\
The results of these appraisals should be collected and analysed nationally & 36 & 22 \\
A research/methodology course should be a mandatory requirement in postgraduate & 69 & 17 \\
education & 67 & 12 \\
There is too much emphasis on service rather than training in current training grades & 66 & 22 \\
My training has equipped me well to manage a paediatric team & 66 & 13 \\
Training in job interview techniques should be part of a paediatric postgraduate & 13 & 64 \\
training programme & 40 & 12 \\
Practical experience is an adequate substitute for formal training in teaching skills & 81 & 6 \\
More emphasis should be put on medical ethic during training & 33 & 31 \\
Communication skills should be formally taught during training & &
\end{tabular}

Yes $=$ agreed or strongly agreed; no=disagreed or strongly disagreed. Numbers do not add up to $100 \%$ because of neutral scores.

least one person. A few people commented on the positive benefits such as making a wider group of friends or meeting their spouses.

Frequent moves also had financial implications both for the NHS and for individuals, particularly with the recession and the difficulty in selling houses. One doctor felt that the change to a lecturer post from the NHS cost him $£ 10000$.

Despite the personal cost most doctors saw moving as beneficial to their training as it gave a wide range of experience. Some felt that a structured local scheme could have provided the same experience whereas others were anxious that by staying in one place, one ran the risk of 'being stuck in a substandard training post'.

Data showed that district general hospital and teaching hospital experience was equally useful $(73 \% ; 73 \%)$ though comments overwhelmingly supported the importance of working in a district general hospital and many felt that is should be compulsory for all doctors. A few people $(3 \%)$ did not find district general hospital experience worthwhile and one or two felt that six months was enough. Although teaching hospital experience was also judged to be useful several paediatricians commented that training there was too specialised and did not train consultants well for a future career in a district general hospital.

Research opportunities were limited and the majority of registrars and senior registrars were unable to take their research sessions. When they were taken the research achieved was often perceived to be of poor quality with little of no supervision or encouragement from seniors. Many comments were received on the poor supervision and called for accreditation of research supervisors to avoid wasting time and publishing papers for the sake of it rather than for their value. The quality of training and supervision was higher for research fellows but many felt that their training in research methodology had been poor.
Those consultants who received good research training were more enthusiastic regarding the need for research during training and commented on the long term benefits in better self management and report writing skills. Overall the opinion was that research opportunities should be available for those who were interested but should not be a compulsory requirement for all consultants.

There was much debate as to the format and content of future training programmes with almost universal agreement that time for training should be protected from service commitments. The concept of regular appraisal and some sort of mentor system for career guidance and personal support was generally accepted although many stressed that the supervisors must also be accredited.

There was an assumption that 'structured training' meant trainer initiated training and a significant number of people stressed the importance of learner centred styles and flexibility within the training period to accommodate individual preferences and complement past experience.

A small number stressed the importance of continuity and clinical responsibility with consultants acting as a supervisory resource rather than 'taking over' during consultation. Others warned of the dangers of becoming supernumerary observers and felt that the experience gained in the current system was one of its strengths.

Almost every consultant felt ill prepared to cope with the non-clinical elements of their consultant role and deficiencies in management, budgeting, leadership, teaching, and supervision skills were commonly mentioned. The vast majority felt well prepared for the general paediatrics, neonatology, and many disease specialty demands in their consultant jobs. Weaker clinical areas are the less disease oriented areas of public health medicine, child psychiatry, dermatology, adoption and fostering, and experience in community based provision.

\section{Conclusion}

There are strong feelings within the body of paediatricians regarding the need for change in content and methods of training. Balancing the needs of the service and the trainees will not be easy given the restraints of reduced junior doctors hours and the shorter more intense training programmes proposed in the Calman report. A curriculum/syllabus for training in paediatrics and its specialties needs to be developed to enable trainers and trainees to

Table 8 Training in paediatric specialties in relation to current job; figures are number of paediatricians

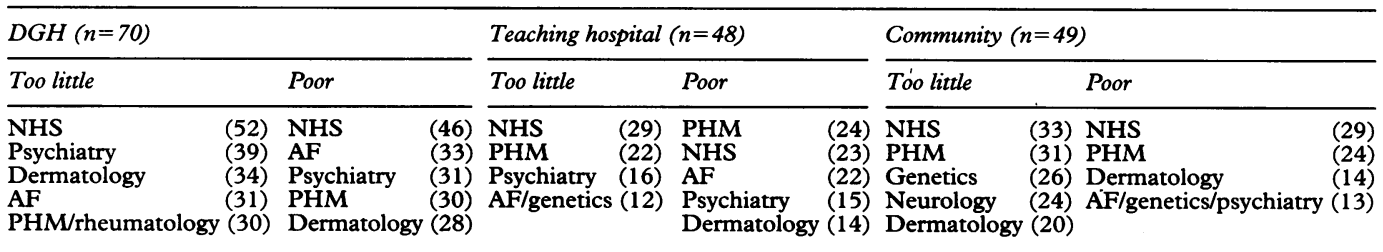

${ }^{\star}$ NHS = NHS management/committee work; $\mathrm{PHM}=$ public health medicine; $\mathrm{AF}=$ adoption and fostering; $\mathrm{DGH}=$ district general hospital. 
Table 9 Specialties identified as providing good training; figures are number of paediatricians

\begin{tabular}{lll}
\hline$D G H(n=70)$ & Teaching hospital $(n=48)$ & Community (n=49) \\
\hline Neonatology (49) & Neonatology/general (33) & General (32) \\
General (47) & Intensive care (26) & Child protection (21) \\
Respiratory (31) & Respiratory/neurology (21) & Neurology (16) \\
Cardiology (27) & Nephrology (20) & Genetics (12) \\
Intensive care (26) & & Psychiatry (12) \\
& & Intensive care (12) \\
\hline
\end{tabular}

$\mathrm{DGH}=$ district general hospital. offers a tide and time for providing our paediatricians for the future with a coherent programme for lifelong learning. Systems need to be installed to enable all of us to study the new developments in clinical medicine, to judiciously introduce innovations into our clinical practice and to evaluate our professional work, not just in our training grades but throughout our professional lifetimes.

Meanwhile, our recently appointed consultants, as reflected in the analysis of the BPA Survey by Lenton, Dison and Haines, feel let down in their preparation for consultanthood. Understandably there are regrets about insufficient experience in managing the health service and in formal training for specialist aspects of their work. However, I would not advocate an over didactic response with more training sessions or closer packed rotations through the specialties. Rather I would encourage all 'students' to take every opportunity to analyse their clinical experience as part of their self development, perhaps guided by a postgraduate syllabus which spans the Calman years in preparation for the CME to come.

There is one detail in the BPA survey on which I would like to comment. It is the unsatisfactory response rate of $67 \%$. We do not know whether the $33 \%$ (nearly 100 paediatricians) who did not reply had experience and views radically different from those reported. If we are to continue to undertake national studies by questionnaires then we need to foster an attitude of commitment to their completion, as a poor response rate amounts to wasted time for respondents and researchers alike. We are, of course, all plagued with questionnaires and perhaps there is here a role for our association in protecting members from questionnaires other than those which are judged to be of national importance.

The $67 \%$ who did reply express particular disappointment over their experience and exposure to research in paediatrics and child health. For those trainees who do not wish to spend years as dedicated research fellows, we should seek to replace the ritual of poorly supervised 'Wednesday afternoon research' by a well devised and efficiently taught course in research methodology, study design, basic statistics, and data handling. Such modules might be tackled in day release courses or blocks of study: for some this might lead to a diploma or master of science degree. This would enable all trainees to enter the consultant ranks appropriately armed to contribute to the advancement of the medicine of childhood. After all, as experience with the British Paediatric Surveillance Unit has shown, clinical research of national importance need not be restricted to those working in major academic departments.

Department of Child Health, Royal Hospital for Sick Children St Michael's Hill, Bristol BS2 8Bf recommendations for a core undergraduate curriculum with a menu of specialist modules, 